\title{
TIPOLOGIA DAS CONSTRUÇÕES VERBAIS EM PORTUGUÊS DO BRASIL: UMA PROPOSTA DE CLASSIFICAÇÃO DO VERBO DAR
}

\author{
Amanda Pontes Rassi* \\ Oto Araujo Vale*
}

Resumo: O presente artigo apresenta uma proposta de classificação das ocorrências do verbo dar em português do Brasil. O objetivo da classificação é indicar uma taxonomia verbal que possa ser expandida e adaptada para a descrição de outros verbos da língua. Com base no modelo teórico-metodológico do LéxicoGramática (GROSS, 1975, 1981), foram analisados os colocados do verbo dar, em suas mais diversas ocorrências, e essa análise levou a uma classificação sintático-semântica do verbo, a qual prevê as seguintes categorias: verbo pleno, verbo-suporte, verbo causativo, construção gramatical, constituinte de expressão cristalizada e constituinte de provérbio. Todas essas categorias podem ser desmembradas em outras subcategorias que abarcam todas as ocorrências do verbo dar no corpus PLN.Br Full.

Palavras-chave: Tipologia verbal; classificação sintático-semântica; verbo dar.

Abstract: This paper presents a proposal for classifying the occurrences of the verb dar (give) in Brazilian Portuguese. The classification aims to provide a verbal taxonomy which can be expanded and adapted for describing other verbs of the language. Based on Lexicon-Grammar theory and methodology (GROSS, 1975,1981 ), the collocates of verb dar (give) were analyzed, and

* Universidade Federal de São Carlos. 
this analysis led to a syntactic-semantic classification, resulting in the following categories: plain verb, support verb, causative verb, grammatical construction, idiomatic expression constituent and proverb constituent. All these categories can be redefined into subcategories relative to all other occurrences of the verb dar (give) in PLN.Br Full corpus.

Keywords: Verbal typology; syntactic-semantic classification; verb dar (give).

\section{Símbolos e convenções}

Adj: $\quad$ adjetivo

Adj-v: $\quad$ verbo deadjetival, ou seja, verbo ligado a um adjetivo morfológica, sintática e semanticamente

Det: determinante

$E$ : $\quad$ numa série de elementos ligados por " +" entre parênteses, designa o não-preenchimento categorial ou lexical de uma dada posição sintática, ou seja, o elemento vazio de uma comutação

$N: \quad$ nome

$N_{i}$ : $\quad$ nome ou grupo nominal que ocupa determinada posição sintática numa dada construção: $\mathrm{N}_{0}$ representa o sujeito, $\mathrm{N}_{1}$ e $\mathrm{N}_{2}$ representam os complementos, nessa ordem

$N^{i}$ : $\quad$ nome ou grupo nominal que ocupa determinada posição sintática numa completiva. Ao contrário da notação $\mathrm{N}_{\mathrm{i}}$ emprega-se o expoente para indicar que se trata dos constituintes de uma oração subordinada

$N_{\text {[agente] }}: \quad$ nome anotado com papel temático de "agente"

$N_{\text {(causal }}$ : nome anotado com papel temático de "causa"

Nbum: nome humano

N-bum: nome não-humano

Nloc: nome locativo

Nnr: nome não-restrito, ou seja, posição sintática que pode ser ocupada por qualquer nome ou sintagma nominal

Npred: $\quad$ nome predicativo

Num: numeral

$V_{\text {dar }}: \quad$ verbo dar flexionado ou não

$V_{\text {dar-se }}: \quad$ verbo pronominal dar-se flexionado ou não

$V_{\text {Icausativol }}$ verbo causativo

Vinf: verbo no infinitivo

Vop: verbo operador 
Vsup: verbo-suporte

$w$ : $\quad$ qualquer sequência não especificada de complementos

+: $\quad$ sinal que indica alternância entre elementos; deve ser lido como ou

=: $\quad$ sinal de equivalência sintática e semântica entre duas frases ou estruturas

$=: \quad$ sinal que especifica a realização lexical de uma categoria ou de uma estrutura

$=/=: \quad$ sinal de não equivalência entre duas frases ou estruturas

\#: $\quad$ marca de fronteira de frase ou de independência

*: $\quad$ marca de não-aceitabilidade

( ): $\quad$ contêm séries de elementos separados por "+" que podem comutar entre si, em dada posição sintática

[ ]: especifica a operação sintática aplicada ou a aplicar

\section{Introdução}

Os verbos ser, ter, estar, fazer, dar, ir e haver são em geral os verbos mais produtivos das línguas românicas. La Fauci e Mirto (2003) já haviam indicado ser, estar, dar, ter e fazer como os mais recorrentes em línguas latinas, mas por meio de uma busca ${ }^{1}$ por frequência de verbos em português do Brasil e português de Portugal, encontramos os dez verbos mais frequentes, nesta ordem: ser, ter, estar, fazer, poder, ir, dizer, haver, dar e dever.

Para propor uma tipologia verbal das construções em Português do Brasil (PB), foi selecionado inicialmente o verbo dar, cuja classificação poderá servir, em parte, para uma classificação geral dos verbos. Por exemplo, esse e vários outros verbos são classificados como plenos em algumas construções, como suporte (ou verbo leve) em outras, como causativo, constituinte de construção gramatical, formador de expressão cristalizada ou constituinte de provérbio. Cada uma dessas categorias será explorada na seção 4.

\footnotetext{
${ }^{1}$ Foi efetuada uma busca por frequência dos lemas verbais em todos os corpora escritos de português do Brasil e de Portugal, disponíveis no AC/DC (Acesso a Corpus/ Disponibilização de Corpus). A busca pode ser reproduzida através do endereço <http://www.linguateca.pt/ACDC/ $>$.
} 
O objetivo desta descrição, em primeira instância, é permitir que os dados da língua sejam incorporados a gramáticas, dicionários e manuais didáticos, e em segunda instância, é contribuir para que eles possam subsidiar a construção de recursos, ferramentas e sistemas de Processamento de Linguagem Natural (PLN).

\section{O modelo teórico-metodológico do Léxico-Gramática}

O modelo do Léxico-Gramática (L-G) foi proposto por Maurice Gross $(1968,1975)$ e tem suas bases no modelo Transformacional e no Distribucionismo de Zellig Harris (1951, 1965). Proposto inicialmente para o francês, vem se expandindo e ganhando espaço no quadro teórico de descrição de várias línguas, tais como italiano, romeno, português europeu, dentre outras.

A ideia introduzida por Gross $(1968,1975,1981)$ de conjugar léxico e gramática na análise e descrição das línguas parte do princípio de que os elementos lexicais podem se combinar gramaticalmente de formas bastante específicas nas línguas, ou seja, nem todo item lexical pode ocupar qualquer posição sintática, devendo adequar-se a determinadas restrições semânticas que a sintaxe lhe impõe, e a restrições sintáticas impostas pela semântica.

A teoria do L-G defende que cada item lexical de uma língua possui uma gramática própria e essa gramática deve ser descrita formalmente; daí decorre o nome Léxico-Gramática, admitindo-se que há uma gramática específica para cada unidade lexical de uma língua. Para isso, reconhece como unidade mínima de análise linguística a frase simples - e não apenas a palavra ou o sintagma. É necessário descrever as propriedades sintáticas e semânticas das frases simples porque delas se podem derivar todas as frases complexas da língua.

Além das contribuições teóricas do L-G, ressalta-se também uma contribuição metodológica do Modelo, que prevê uma formalização dos dados da língua em matrizes binárias cujas linhas correspondem às entradas lexicais e em cujas colunas apresentam- 
se as propriedades sintático-semânticas; na intersecção entre uma linha e uma coluna, marca-se "+" para a aceitabilidade da propriedade e "-" para a inaceitabilidade da propriedade. A formalização dos dados em tábuas do Léxico-Gramática configura um método interessante de descrição de línguas porque os dados podem ser manipulados automaticamente por ferramentas e sistemas de Processamento de Linguagem Natural (PLN).

\section{Metodologia}

A lista de ocorrências a serem analisadas foi inicialmente recenseada em corpus e posteriormente foi acrescida de outras construções que reconhecemos intuitivamente como legítimas na língua portuguesa, portanto é uma pesquisa empírica quantitativa e qualitativa que visa a identificar as ocorrências do item lexical dar, juntamente com seus colocados, e propor uma tipologia verbal para essas ocorrências.

O corpus adotado para o recenseamento das ocorrências é o PLN.Br FULL (BRUCKSCHEN et al., 2008), desenvolvido por pesquisadores do Núcleo Interinstitucional de Linguística Computacional (NILC) ICMC/USP - São Carlos. O PLN.Br FULL é constituído de artigos jornalísticos e possui 96.868 textos com 26.425.483 tokens distribuídos em 12 anos de publicações do Jornal Folha de São Paulo - 1994 a 2005. Eventualmente também foram utilizados os motores de busca Google e Yahoo Search para efetuar pesquisas específicas na web.

Como ferramenta de auxílio ao recenseamento dos dados, foi utilizado o Unitex 3.1 Beta (PAUMIER, 2002), que permite a busca e o pré-processamento ${ }^{2}$ de qualquer lexia em grandes

\footnotetext{
${ }^{2} \mathrm{O}$ pré-processamento no Unitex é feito por meio de segmentação dos vocábulos, segmentação das sentenças, reconhecimento dos lemas, reconhecimento de todas as flexões e derivações dos vocábulos, identificação de palavras compostas, identificação de neologismos, identificação da categoria
} 
corpora em tempo real. O Unitex possui um concordanciador que possibilita ao usuário fazer buscas rápidas por lexias ou expressões regulares previamente definidas. Dessa forma, é possível encontrar todas as ocorrências do lexema dar, em suas formas verbais e nominais, conjugado ou não, flexionado ou não.

No corpus, foram encontrados 66.798 tokens de formas idênticas às formas conjugadas de dar. Dessas, cerca de 12.000 ocorrências foram descartadas por não se tratarem de verbos, e sim de pronomes ou nomes homógrafos, tais como as formas desse, desses, deste, destes, dado, dados, DOU etc., como no exemplos:

(1) O Decreto $\mathrm{n}^{\mathrm{0}} 7.312$ foi publicado no $D O U$ em 23/09/2010.

(2) $[\ldots]$, segundo dados divulgados pelo IBGE.

(3) Em junho desse ano três pessoas morreram por leishmaniose.

As buscas foram feitas por colocados à direita do verbo, flexionado em todas as suas formas verbais e nominais. Haja vista que a ordem sintática canônica do português é Sujeito, Verbo, Objeto (SVO), interessava-nos analisar o que vem após o verbo dar, que geralmente é o complemento verbal, daí buscar pelos colocados à direita.

\section{Princípio de classificação}

Com base na análise do corpus, foi possível estabelecer seis tipos de ocorrências do verbo dar. Essa análise é de base lexicográfica, e investiga o item lexical dar em dois níveis

gramatical das palavras, dentre outras tarefas realizadas automaticamente. $\mathrm{O}$ pré-processamento só é possível porque o Unitex dispõe de recursos léxicocomputacionais, como gramáticas locais, dicionários de formas simples, dicionários de formas compostas, de formas canônicas e flexionadas etc. 
conjuntamente: sintático e semântico. As seis categorias serão apresentadas no decorrer desta seção:

\subsection{Verbo pleno}

O L-G identifica os verbos plenos por suas restrições de seleção de sujeito e pelo conteúdo semântico do verbo, ou seja, para que seja considerado como verbo pleno, $o V_{d a r}$ deve apresentar um sujeito humano (Nhum), agente, voluntário, que é responsável pela transferência física de um objeto concreto a um beneficiário. A forma plena mais prototípica do verbo dar em PB é com complemento dativo:

(4) Um dos islamitas que atacaram o shopping de Nairóbi deu um chocolate a um menino de 4 anos.

(5) A Lourdes, psicanalista, deu um computador às sobrinhas.

Nesses dois casos, transfere-se a posse do objeto (chocolate ou computador) das mãos de $N_{o}$ (Um dos islamitas que atacaram o shopping de Nairóbi ou A Lourdes) para as mãos de $N_{2}$ (um menino de 4 anos ou as sobrinhas). Não foi realizada análise quantitativa no corpus para averiguar em quantas ocorrências o verbo dar aparece com dativo, mas estima-se que esse número é muito inferior à sua frequência como verbo-suporte.

Há ainda outras duas formas de o verbo dar se apresentar como pleno: i) quando indica um acontecimento, evento, ocorrência - e nesse caso há duas construções sintáticas diferentes - ou ii) quando o verbo indica resultado numérico. Em i), destacam-se as construções como (6) e (7), de um lado, que podem ser formalizadas como $\left[V_{d a r}(E+D e t) N_{i}\right]$; e, por outro lado, construções como (8) e (9), formadas por $\left[N_{i} V_{\text {darse }}\right]$ :

(6) Os seguranças tentaram separar e deu uma confusão.

(7) Hoje vou postar sobre um assunto que já deu briga com Habibi. 
(8) O fim da filial brasileira se deu por 'abuso econômico' do Uol.

(9) O solstício de verão, no hemisfério Norte, dá-se aproximadamente no dia 21 de junho.

Como exemplos do verbo dar indicando resultado numérico de uma operação matemática, citam-se:

(10) Dois e dois nunca dá cinco.

(11) Se puser na ponta do lápis, 3 mais 8 dá 11 .

\subsection{Verbo-suporte}

Além de transferir objetos concretos, a mesma estrutura sintática com argumento dativo pode ser usada para expressar a transferência de informação, conceito, valor, ou outra entidade abstrata, e não apenas objetos ou coisas concretas:

(12) O governador Raimundo Colombo deu uma informação "genérica" para o Aeroporto Regional Sul.

(13) Alessandro Cambalhota deu conselbos ao atacante Maurides.

Em nenhum dos casos, aquilo que era posse inicialmente do sujeito $N_{o}$ (O governador Raimundo Colombo ou Alessandro Cambalbota) deixa de ser propriedade sua para passar a ser propriedade do destinatário $N_{1}$ (o Aeroporto Regional Sul ou o atacante Maurides), pois informação e conselbos podem ser compartilhadas, mas no final do processo ambos - possuidor inicial e possuidor final - detêm a mesma informação, ideia, ou valor. Nesses casos, o $V_{d a r}$ é denominado verbo-suporte (ou verbo leve).

Note-se que a diferença sintática fundamental entre as construções com verbo pleno (4) e (5) e as construções com verbosuporte (12) e (13) está na classificação do $N_{i}$ posterior ao verbo. Nas construções com verbo pleno, o $V_{\text {dar }}$ exige 3 argumentos, 
sendo $N_{o}$ (sujeito agente), $N_{1}$ (objeto da dação) e $N_{2}$ (beneficiário). Nas construções com verbo-suporte, é o predicado complexo [Vsup $(E+D e t)$ Npred] quem seleciona seus argumentos, exigindo apenas $N_{o}$ (sujeito agente) e $N_{1}$ (beneficiário). Suas sintaxes podem ser assim formalizadas:

- Construções com verbo pleno com complemento dativo: $\left[N_{o} V_{d a r}(E+D e t) N_{1}(a+p a r a) N_{2}\right]$

- Construções com o verbo-suporte: $\left[N_{o}\right.$ Vsup $(E+D e t)$ Npred Prep $\left.N_{1}\right]$

O conceito de Vsup, porém, não se restringe ao traço abstrato do Npred. Há diferentes testes ${ }^{3}$ que podem ser usados para identificar os verbos-suporte (ou verbos leves), como a substituição da construção com Vsup por um verbo pleno correspondente (como dar um abraço = abraçar, ou dar um beijo = beijar); a estreita correlação entre o Npred e o sujeito da construção (por exemplo, em Pelé deu um chute na bola, Pelé só pode dar o seu próprio chute na bola, interditando a construção *Pelé deu o chute do Neymar na bola); as restrições sobre os determinantes (em Ana deu uma passeada no parque, o determinante uma é obrigatório); dentre outros testes.

Há diferenças conceituais entre as nomenclaturas de verbo leve e verbo-suporte. O conceito de verbo-suporte (support verb) foi definido por Gross (1981), e se trata de um conceito sintático, por ser um "verbo que se combina com um nome para tornar-se um predicado completo, dado que alguns substantivos e adjetivos podem evocar argumentos internos, mas precisam ser associados a um verbo para evocar o argumento externo, isto é, o sujeito"

\footnotetext{
${ }^{3}$ Para consultar os testes de identificação de verbo-suporte, consultar Baptista (2005).

${ }^{4}$ Tradução nossa. Do original: "a support verb is the verb that combines with a noun to enable it to fully predicate, given that some nouns and adjectives may evoke internal arguments, but need to be associated with a verb to evoke the external argument, that is, the subject".
} 
(DURAN et al., 2011). Já o conceito verbo leve (light verb) é atribuído a Jespersen (1965), e é considerado um conceito semântico, por ser um verbo polissêmico sem um significado prototípico (DURAN et al., 2011). Nesta análise, adotamos a noção de verbo-suporte por considerarmos que ele serve, de fato, para suportar as marcas verbais de tempo, modo, pessoa e aspecto, as quais não podem ser marcadas no nome predicativo. Vale ressaltar que, diferentemente de outros autores, consideramos que o conceito de verbo-suporte não é apenas sintático, possuindo também sua contraparte semântica. ${ }^{5}$

O conceito de verbo-suporte não é consensual na literatura. Há autores que pregam desde o esvaziamento completo do verbo até o processo de dessemantização, em que o verbo perde parte de seus traços semânticos. De fato, há diferentes tipos de verbo-suporte: Ruppenhofer et al. (2006) distinguem cinco classes de verbosuporte (plain vanilla, aspectual, ponto de vista, registro e causativo); Gross (1998) identifica outras cinco classes, sendo algumas coincidentes (aspecto, causativo, verbos suporte intensivos, verbos suporte conjuntivos e modalidades especializadas), além de tratar das relações semânticas entre verbos-suporte.

No corpus são encontradas: i) construções construídas com o verbo-suporte dar e um nome predicativo autônomo, como dar tilt, dar toco, dar sopapo, dar piparote; ii) construções com verbo-suporte que admitem nominalização, como dar um murro/ esmurrar, dar um tiro/atirar, dar um sinal/sinalizar, dentre outros; iii) nomes predicativos acrescidos do sufixo $-d a$, que podem indicar o aspecto verbal - como dar uma passada, dar uma lida, dar uma olhadinha - ou significar bater com determinado objeto - como dar uma martelada, dar uma cadeirada, dar uma paulada.

\footnotetext{
${ }^{5}$ Para maiores esclarecimentos, consultar Gross (1998), que trata da "Função semântica dos verbos-suporte".
} 
Vale ressaltar que as classes semânticas não são fechadas, podendo ser extintas, subdivididas, combinadas ou podem ser criadas outras classes na medida em que as ocorrências de nomes predicativos no corpus se diversificarem. Dos 2.300 colocados nominais com o verbo dar identificados no corpus, 1.352 foram classificados como construções com Vsup.

\subsection{Verbo causativo}

Há divergências teóricas quanto ao estatuto do verbo causativo, podendo ser classificado como um tipo particular de verbosuporte ou como uma categoria distinta da categoria dos verbossuporte, mas que mantêm uma fronteira tênue com estes últimos.

Gross (1981, p.45) explica que existe uma operação de fusão, em que "um processo de combinação de frases pode modificar o número de argumentos de um verbo. Este processo combina entre si dois verbos ou um verbo e um argumento, e um dos dois elementos desaparece, daí o nome fusão". Essa operação é formalizada por Baptista como:

[Fusão]

Nnr Vop \# $\mathrm{N}_{0}$ ser Adj w

$(\mathrm{Nnr})_{0}$ Adj-v $\left(\mathrm{N}^{0}\right)_{1} \mathrm{w}$

(14) =: $\quad$ A nova legislação tornou \# O divórcio é banal.

(14) $\quad$ A nova legislação banalizou o divórcio.

Aplicada ao verbo dar, essa operação de fusão pode indicar uma causa, provocada por um argumento anotado necessariamente com papel semântico de "causa" como em (15), ou uma atribuição, em que um agente atribui determinada característica ao objeto, como em (16).

[Fusão]

$\mathrm{N}_{\text {[causa] }} \mathrm{V}_{\text {[causativo] }} \# \mathrm{~N}_{0}$ ter Npred

(15) $=$ :

$\left(\mathrm{N}_{\text {[causal }}\right)_{0} \mathrm{~V}_{\text {[causativo] }}$ Npred Prep $\left(\mathrm{N}^{0}\right)_{1}$

(15) $=$

O exercício físico causa \# Ana ter sede.

O exercício físico dá sede em Ana. 
[Fusão]

(16) =:

$\mathrm{N}_{\text {[agente] }}$ Vop \# $\mathrm{N}_{0}$ ter Npred

$(16)=$

$\left(\mathrm{N}_{\text {[agente] }}\right)_{0} \mathrm{~V}_{\text {[causativo] }}$ Npred Prep $\left(\mathrm{N}^{0}\right)_{1}$

Zé fez \# O processo ter transparência.

Zé deu transparência ao processo.

Recorre-se à operação de fusão para justificar que existe uma frase de base, que é constituída por um verbo-suporte e um nome predicativo (Ana tem sede e Oprocesso tem transparência), mas esse verbo-suporte nãoé o dar. O verbo dar, nesses casos, possui conteúdo semântico causal, pois indica a causa da frase de base. É importante explicitar qual seria o verbo-suporte da construção de base (nos dois casos, o verbo ter) porque o modelo do Léxico-Gramática descreve apenas as predicações de base. Nas tábuas do L-G devem constar as entradas ser banal, ter sede, ter transparência, mas não as construções causativas dar banalidade, dar sede e dar transparência, porque elas são transformações das formas básicas.

As construções classificadas como causativas se subdividem em três categorias semânticas diferentes, baseadas no tipo semântico dos Npred: i) a classe das doenças; ii) a classe de sentimentos, sensações e emoções; iii) a classe das atribuições ou características. Seguem-se dois exemplos representantes de cada uma dessas classes, respectivamente.

(17) Comer sal dá pressão alta.

(18) O peixe cru me deu dor de barriga.

(19) Elogios the dão alegria.

(20) A escuridão do quarto me deu medo.

(21) O advogado deu celeridade ao processo.

(22) O editor deu uma cara nova à revista.

Citam-se outros nomes pertencentes à classe i) afasia, AIDS, alergia, câncer, diabetes, diarreia, bemorragia, sapinbo, sarampo, úlcera e outros; à classe ii) aborrecimento, angústia, ânimo, ansiedade, aperto no coração, apetite, arrependimento, 
arrepio, cansaço, carência, culpa, delírio, desconforto, desejo, desgosto e outros; e à classe iii) afetividade, amplitude, arejamento, autenticidade, autonomia, autoridade, capacidade, cientificidade, consistência, concretude, legalidade, dentre outros.

Dos 2.300 colocados com o verbo dar, 930 se classificam como construções causativas, pertencentes a uma das três subclasses.

\subsection{Construção gramatical}

O corpus apresenta frequência alta de construções gramaticais, ou seja, expressões construídas por uma sequência sintática relativamente fixa, porém cujas posições sintáticas são instanciadas por diferentes unidades lexicais. Uma das construções gramaticais mais recorrentes é a formada por $\left[V_{d a r}\right.$ (para+pra) Vinf], tal como se apresenta em:

(23) Através dele dá para descobrir o jeito da pessoa.

(24) Dessa forma dá para assistir a um filme dispensando a TV.

Nesses casos, o dar se apresenta como verbo modal ou modalizador semelhante ao can/may do inglês, e pode ser usado em português em substituição a ser possível ou poder. Dessa forma, o verbo dar indica capacidade ou competência, e toda a expressão deve ser classificada como construção gramatical.

Há também no corpus outra construção gramatical que mantém estrutura sintática semelhante à das construções anteriores; são expressões constituídas com a mesma estrutura $\left[V_{d a r}(\right.$ para + pra $)$ Vinf $]$, porém apresentam significado distinto dos modalizadores apresentados anteriormente. Essas construções geralmente são constituídas pelo verbo dar no passado e todas as ocorrências apresentam sujeito simples ou composto, diferentemente das construções anteriores, que apresentavam uma oração subjetiva como sujeito da oração principal ou apresentavam sujeito indeterminado. 
(25) Agora a cidade de São Paulo deu para andar de lotação, de Kombi.

(26) Essa molecada carioca deu para aterrorizar o Rio.

(27) A esquerda socializada deu para crer que provocaria mudanças sociais.

Essa construção poderia ser parafraseada pela expressão começou $a$, seguida da frase, que é sempre iniciada por Vinf. A criação de construções como essa provém da necessidade do falante de marcar o aspecto verbal - neste caso, incoativo - em algum elemento da língua, já que, em língua portuguesa, nem todos os aspectos podem ser marcados no próprio verbo.

Ambas as construções (a modal e a incoativa) também aparecem no corpus com a preposição de em vez de para, como nos exemplos seguintes:

(28) Não deu de gravar o vídeo do trajeto, pois ainda estou sem suporte de câmera.

(29) O caldo ficou ralo e não deu de fazer a cobertura.

(30) Lady Gaga agora deu de fazer body modification.

(31) Meu filho começou a ir à escola e agora deu de fazer xixi na cama.

Há um grupo seleto de construções identificadas no corpus que apresentam a mesma estrutura sintática de $\left[N_{o} V_{d a r} d e\right.$ Vinf], porém com outro valor semântico, em que o verbo dar corresponde semanticamente a oferecer e o verbo na posição de Vinf pode ser nominalizado, como é o caso de:

(32) Se tem gente com fome, a gente dá de comer. $=$ Se tem gente com fome, a gente oferece comida .

(33) Se o menino estava com sede, ele dava de beber. $=$ Se o menino estava com sede, ele oferecia bebida . 
(34) Vem esse tanto de gente e eu tenho que achar o que dar de jantar.

$=$ Vem esse tanto de gente e eu tenho que achar o que oferecer como janta.

Se os exemplos construídos com $\left[V_{\text {dar }}(\right.$ para + pra $)$ Vinf $]$ indicavam possibilidade e podiam ser substituídos pelos verbos conseguir, poder e ser possível, as construções com $\left[N_{o} V_{d a r}\right.$ (para+pra) Num], diferentemente, referem-se a quantidade suficiente, indicando que determinada quantidade (de coisas) é suficiente para outra determinada quantidade (de pessoas, por exemplo).

(35) O carro-chefe é o pintado na brasa, que dá para duas pessoas.

(36) O prato é individual, só dá pra 1.

(37) $20 \mathrm{~kg}$ dá para 20 soldados em combate e ainda sobra.

A mesma ideia de suficiência, por vezes, apresenta-se em uma construção reduzida da estrutura anterior, resultando apenas no verbo dar. Pelo contexto, é possível inferir que o sentido empregado pelo verbo dar é o mesmo que indica suficiência de quantidade:

(38) Que dá, dá.

(39) Coloquei só uma receita, não sei se dá.

(40) É só acrescentar mais água no feijão, aí é certeza que dá.

Outra estrutura sintática semelhante às duas anteriores é a expressão construída pelo verbo dar, seguida da preposição para e de um locativo, designado por Nloc, formalizado como $\left[N_{0} V_{d a r}\right.$ (para+pra) (E+Det) Nloc]. O elemento locativo expressa local, direção, rumo, e a construção toda indica a direção para onde determinado objeto está voltado, para onde possui vista. 
(41) ela permaneça de pé, sozinha sob o umbral da porta que dá para o campo.

(42) e fomos grudados nele até a porta que dá para o elevador de serviço.

(43) os quartos ganham algum charme com a varanda que dá para o rio.

(44) Jantar no terraço do hotel, que dá para os jardins, é um prazer.

As ocorrências de construções gramaticais no corpus não foram contabilizadas, bem como não constam na contagem dos 2.300 colocados. Não foi feita análise quantitativa desses casos porque a lista de colocados constitui-se apenas de verbo seguido de nome, não admitindo construções mais complexas.

\subsection{Expressões cristalizadas}

Expressão cristalizada (EC), também chamada de expressão idiomática, é uma unidade lexical elementar, e "embora consista em mais de uma palavra, apresenta uma coesão interna de palavras únicas" (CRUSE, 1986, p. 38). Pode haver a coincidência de o significado de uma EC corresponder aos significados dos itens lexicais que a compõem, porém essa correspondência nem sempre acontece, o que nos permite inferir que o significado das ECs é total, não podendo ser mensurado por meio de suas partes.

Assim, elas são chamadas de cristalizadas porque realmente contêm elementos fixos - tais como cristais - e aceitam pouca mobilidade em seus constituintes. Como sugere Vale (2001), as expressões cristalizadas devem ser classificadas como sendo um único signo, e não como um conjunto de palavras que constituem uma forma verbal composta.

No corpus, foram encontradas ECs verbais, adjetivais e adverbiais cuja estrutura exige a presença do verbo dar e de outros 
elementos fixos ou relativamente fixos, mas a grande maioria delas são ECs verbais, como as que se seguem:

(45) $[\ldots]$ pensando que esse assunto já tava resolvido, deu com os burros n'água e teve que voltar.

(46) Desprestigiado, o aloprado ameaça dar com a língua nos dentes.

(47) Você entende que dar a mão à palmatória não te diminui, te evolui.

(48) Cansei de dar murro em ponta de faca e vou entrar na dos africanos.

Outros exemplos são: dar tiro no pé, dar para o gasto, dar o braço a torcer, dar nome aos bois, dar tapa na pantera, dar a cara a tapa, dar bola fora, dar um passo maior que a perna, dar tapa com luva de pelica, dar uma de João sem braço, dar a volta por cima, dar ponto sem nó, dar a cara pra bater, dar calo na vista, dar um tiro na água.

Em todos esses exemplos, o único elemento livre é o argumento $N_{o}$ na posição sujeito. Em outras expressões cristalizadas, pode haver outra posição sintática que não é preenchida obrigatoriamente pelo mesmo vocábulo. É o caso de (49), (50), (51) e (52), que possuem $N_{o}$ e/ou $N_{1}$ que não são fixos.

(49) Deu a louca em secretários de Ilhéus e Ibirataia.

(50) O governo do presidente Lula deu as costas para os ricos.

(51) Saído do longínquo sertão da Bahia, deu com os costados em Santana do Ipanema.

(52) O visitante atravessou uma porta e deu de cara com um cenário diferente.

As expressões dar a louca em $N_{1}$, dar as costas para $N_{1}$, dar com os costados em $N_{1}$ e dar de cara com $N_{1}$ devem ter a 
posição de $N_{1}$ preenchida, respectivamente, por: Nhum, Nhr, Nloc e $N n r$.

Essa última expressão admite duas variações sintáticas. $\mathrm{O}$ elemento de cara na expressão $\left[N_{o} V_{d a r}\right.$ de cara $\left.\operatorname{com} N_{1}\right]$ pode ser omitido, restando apenas $\left[N_{o} V_{d a r} \operatorname{com} N_{1}\right]$, sem alterar o significado da expressão.

(53) quando se vira e dá com a minha cara inarredável e curiosa.

(54) Ao entrar, deu com o amante da mulher na sua frente.

Outra possibilidade de reconstrução sintática dessa expressão é $\left[N_{o} V_{\text {dar }}\right.$ com a cara em $\left.N_{1}\right]$, que significa "bater com a cara em", diferentemente de $\left[N_{0} V_{\text {dar }}\right.$ de cara $\left.\operatorname{com} N_{1}\right]$, que remete a "encontrar-se com", "estar de frente a". Em geral, $N_{o}$ é um Nbum, enquanto $N_{1}$ é preenchido por nome não-humano (N-bum).

(55) Errou o passo e deu com a cara no chão.

(56) Você já deu com a cara naquelas portas de vidro?

(57) Quem nunca deu com a cara no poste?

No corpus também foram encontradas expressões que coocorrem com o verbo dar, porém são expressões cristalizadas substantivais, ou seja, o $V_{d a r}$ não é um elemento fixo obrigatório na expressão. Citam-se alguns exemplos: dar casa, comida e roupa lavada, dar chá de cadeira, dar tchau e bênção. Uma prova de que o verbo dessas construções não é um elemento fixo é que todas elas podem sofrer conversão ou ocorrer com outros verbos: ganhar casa, comida e roupa lavada, levar um chá de cadeira, falar tchau e bênção.

Vale ressaltar que as expressões cristalizadas constituídas de apenas dois elementos, tais como (58), (59) e (60) $-V_{d a r} N-$ foram incorporadas à listagem de 2.300 colocados com o verbo dar. Nesse rol, apenas 18 colocados são classificados como expressões cristalizadas. 
(58) Fui fazer uma apresentação, mas deu zebra, porque fiquei muito nervoso.

(59) Não foi a primeira vez que Goldenberg deu um furo.

(60) Eu cantei a "Traviata" e o jornal deu uma rata elogiando o meu francês.

A expressão [ $V_{d a r}$ a entender] é considerada uma EC, porém admite também variações como [ $V_{d a r} a$ ver $],\left[V_{d a r} a\right.$ crer $] \mathrm{e}$ [ $V_{d a r}$ a conbecer]. A forma mais frequente é [ $V_{d a r} a$ entender].

(61) Lula dá a entender que tem mais opções petistas do que Palocci.

(62) Ele dava a entender sua mágoa diante da negação dos cargos.

(63) Os oficiais comunistas deram a conbecer a nacionalidade de 15 prisioneiros.

(64) Os diálogos do filme dão a ver um homem de grande inteligência.

(65) e ele dava a crer que estava possuído pelo demônio.

Nas ECs formadas por $\left[N_{o} V_{d a r} u m a d e(N+A d j)\right]$, os elementos dar uma de são fixos, admitindo variação apenas do sujeito da frase e do nome ou adjetivo subsequente à preposição de. O preenchimento da posição de $N_{1}$ é bastante livre, apesar de possuir restrições semânticas.

(66) Cristovam Buarque (PT-DF) dá uma de tucano.

(67) Ela fica dando uma de meiga pra ver se arruma casamento.

(68) Finalmente alguém deu uma de sábio na reunião.

O sujeito da expressão, por exemplo, só pode ser um nome humano (Nbum), que tenha a capacidade de fingir. Já a 
posição de segundo argumento geralmente é preenchida por um adjetivo ou um substantivo do qual se possa extrair uma característica que funcione como qualificativa. Todas as construções com $\left[N_{o} V_{d a r}\right.$ uma de $\left.(N+A d j)\right]$ indicam "fingir ser", "fazer parecer ser" e poderiam ser parafraseadas por outra expressão com o verbo fazer, como em:

(66') Cristovam Buarque (PT-DF) se faz de tucano.

(67') Ela fica se fazendo de meiga pra ver se arruma casamento.

(68') Finalmente alguém se fez de sábio na reunião.

O corpus apresenta número significativo de ocorrências da EC $\left[N_{o} V_{d a r} N_{1}(c o m o+p o r) N_{2}\right]$, em que $N_{1}$ é necessariamente um substantivo, seguido da conjunção como ou por, e seguido de outro nome $\left(N_{2}\right)$ que é necessariamente um qualificativo.

(69) geração que dá as conquistas da Guerra Fria como garantidas.

(70) Delfim Netto é mais enfático e dá a falência do país como favas contadas.

(71) [...] repetidos elogios da crítica, que dá sua aparição como certa.

(72) O PSDB dá por certa a filiação do ministro Walter Barelli.

(73) Criança é dada por desaparecida na grande São Paulo.

As ECs formadas por comparações numéricas entre dois elementos, que podem ser humanos ou não, ocorrem sob duas formas diferentes: na presença ou na ausência do segundo numeral, que serve de base de comparação. Em ambos os casos, a construção possui o mesmo significado de que o primeiro elemento da comparação é melhor que o segundo elemento, e podem ser formalizadas como $\left[N_{o} V_{d a r}\right.$ de $(\mathrm{dez}+\mathrm{cem}+\mathrm{mil})(E+a$ zero) em $N_{1}$ ] 
(74) Zé dá de mil em Rui.

(75) Zé dá de dez a zero em Rui.

A última expressão a ser discutida é composta pelo $V_{d a r}$ seguido de frase completiva, que pode ser introduzida por o que ou no que, seguido de algum Vinf. Há restrições semânticas em relação aos verbos que podem assumir essa posição de Vinf dentro da completiva. A maior frequência no corpus ocorre com os verbos falar e pensar:

(76) Paulo inovou no processo de criação dos suínos e deu no que falar.

(77) A ação já foi realizada na Ufla, Ufop e UFSJ e deu o que pensar nos mestrandos e doutorandos.

Esporadicamente outros verbos (inclusive o próprio $V_{d a r}$ ) assumem a posição de Vinf, com frequência muito mais baixa, e todas elas podem ser representadas por $\left[N_{o} V_{d a r}(o+n o) q u e\right.$ Vinf $]$. Ressalta-se que a posição $N_{o}$ nunca é preenchida por Nbum, aceitando apenas $N$-bum ou completiva como sujeito.

(78) O trabalho voluntário deu o que fazer.

(79) A discussão já deu o que tinba que dar.

(80) ele estava se destacando no mercado musical nacional e deu no que deu.

As demais ECs encontradas no corpus mantêm a estrutura sintática $\left[N_{0} V_{\text {dar }}\right.$ prep $\left.C_{1} N_{1}\right]$ e podem admitir certa mobilidade entre seus constituintes, resultando em $\left[N_{0} V_{d a r} N_{1}\right.$ prep $\left.C_{1}\right]$, ou seja, eles autorizam algum elemento livre entre $V_{d a r}$ e prep, porém $C_{1}$ é sempre um complemento fixo obrigatório.

(81) Quem apresentou algo sem orçamento deu de bandeja os argumentos pra CBF mudar o palco.

(82) Não acho que a CPI do orçamento deu em pizza. 
(83) O ministro deu pra trás quando foi questionado sobre a aprovação do projeto.

Outros exemplos da classe $\left[N_{0} V_{\text {dar }}\right.$ prep $\left.C_{1} N_{1}\right]$ são: dar de graça, dar de brinde, dar de lambuja, dar na vista, dar na telba, dar na cabeça, dar na cachola, dar na veneta, dar nos nervos, dar de ombros, dar no couro, dar na escalada, dar no(a) mesmo(a), dar por si, dar em nada e dar no pé. Essas ECs não foram computadas na lista de 2.300 colocados por apresentarem preposição em sua constituição, ao passo que os colocados são constituídos apenas por $\left[V_{d a r} N\right]$.

\subsection{Provérbios}

A diferença entre as expressões cristalizadas e os provérbios não é consensual na literatura. Há autores que consideram essa diferença pela extensão de cada um - em geral os provérbios são maiores do que as expressões; outros consideram que a diferença entre eles está na função social de cada um, ou no conteúdo moralizante ou sentencioso dos provérbios, o que não se verifica nas expressões cristalizadas.

Neste trabalho, consideramos que a diferença primordial entre provérbios e expressões cristalizadas está na quantidade de informação que cada um veicula. A EC substitui uma palavra ou um sintagma numa frase, enquanto o provérbio é dotado de uma proposição completa. Os provérbios também podem veicular duas ou mais proposições ao mesmo tempo.

(87) Fiquei meio assim com essa ideia de que a vida é um presente, porque outro dia também ouvi de um mendigo agradecido pelas sobras de um almoço: "cavalo dado não se olba os dentes".

(88) Edir Macedo tenta explicar o sentido da sua famosa frase: "ou dá ou desce".

(89) O desmiolado que arremessou a lata de cerveja na cabeça de Luxemburgo deu o tapa e escondeu a mão. 
(90) Mais do que dar o peixe ou ensinar a pescar, o fundamental é ensinar a pensar.

Foram encontrados no corpus outros 16 provérbios cuja constituição exige o verbo dar, conjugado em diferentes tempos, modos e pessoas, tais como: dar a César o que é de César, dar com uma mão e tirar com a outra, dinbeiro não dá em árvore, jabuticaba não dá em cacho, você dá a mão e ele quer o braço, dentre outros.

\section{O continuum verbal}

Para propor a classificação acima, consideramos que existe um continuum entre as categorias verbais. Existem os verbos plenos, os verbos-suporte, os causativos e assim por diante; as fronteiras entre uma classe e outra, porém, não podem ser determinadas por meio de limites exatos. Este trabalho parte do pressuposto de que existem fronteiras tênues entre uma categoria e outra.

Neves (1996) trata desse continuum entre construções livres e construções com verbo-suporte. Gross (1982, p.160) estende esse continuum até a expressão cristalizada: “(...) a delimitação não é simples de traçar, pois sintaticamente parece existir um continuum entre as formas fixas e as livres". ${ }^{6}$ Vale (2001) esclarece esse continuum por meio da sequência de exemplos que vai desde verbo pleno (90), passando por construções com verbo-suporte em diferentes níveis (91), (92), (93), (94), (95) até expressão cristalizada mais e menos permutável (96) e (97):

(90) O presidente Muammar Khaddafi deu US\$ 1 bilbão a Farrakhan em 1996.

\footnotetext{
${ }^{6}$ Tradução nossa. Do original: "la délimitation n'est pas simple à tracer, au point que syntaxiquement il semble exister un continuum entre les formes figées et libres".
} 
(91) A comerciante invadiu a avenida e deu um abraço no líder.

(92) Conde falou da transformação do Rio e deu garantias da melhora da infraestrutura.

(93) Pont deu início ao terceiro mandato consecutivo do PT na capital gaúcha.

(94) Pessoas ligadas ao ex-prefeito afirmaram que ele dava prioridade ao iogurte.

(95) (...) no Cairo, dei um vexame diante de 4.000 anos de história condensados nas pirâmides.

(96) Para esquecer que hoje é a data mais nefasta do ano, em vez de ficar dando de joão sem braço, escolha uma das opções abaixo e mande ver.

(97) Serjão é um cara que dá a cara pra bater, que briga, que discute.

Em trabalhos futuros, pretendemos propor uma modelagem desse continuum que abarque todas as classes em que o verbo dar se classifica, com estado inicial partindo de verbo pleno ou construção livre até o estado final classificado como provérbio, em termos de fixidez dos constituintes.

\section{Considerações finais}

Este trabalho pretendeu esboçar uma tipologia verbal do verbo dar, a partir de sua análise e descrição. Os resultados da análise levaram a uma distinção entre seis categorias às quais o verbo dar pertence: verbo pleno, verbo-suporte, verbo causativo, construção gramatical, constituinte de expressão cristalizada e constituinte de provérbio. Essa tipologia pode ser expandida para abarcar outras categorias e servir de base para a classificação de outros verbos. 
No corpus foram encontradas outras construções que não se enquadram em nenhuma dessas classes e também não possuem frequência significativa para constituírem uma nova classe. Citam-se alguns exemplos: deu duas horas, esta estrada dá em São Paulo, na festa deu mil pessoas, minha vida dá um filme, a lâmpada deu um estouro, deu bicho na laranja, dentre outros. Esses casos foram considerados como residuais, mas serão descritos posteriormente em trabalhos futuros.

Levando-se em conta que o verbo dar é um dos 10 verbos de maior frequência em português, reconhece-se a necessidade de descrevê-lo para que essa descrição possa embasar a descrição de várias outras unidades lexicais da língua.

Pretende-se ainda, em trabalhos futuros, formalizar essa descrição em tábuas do Léxico-Gramática (GROSS, 1981), a fim de subsidiar aplicações ou recursos computacionais, tais como dicionários legíveis e tratáveis por máquina, anotadores de papéis semânticos, recursos léxicos estruturados, parsers, simplificadores textuais e outros.

\section{Referências}

BRUCKSCHEN, M.; MUNIZ, F.; SOUZA, J. G. C.; FUCHS, J. T.; INFANTE, K.; MUNIZ, M.; GONÇALVES, P. N.; VIEIRA, R.; ALUÍSIO, S. M. Anotação linguística em XML do Corpus PLN-BR. Série de relatórios do NILC, NILC-TR-09-08, 39p, 2008.

CRUSE, D. A. Lexical semantics. Cambridge, Inglaterra: Cambridge University Press, 1986.

DURAN, M. S. et al. Identifying and analyzing Brazilian Portuguese complex predicates. In: Proceedings of the workshop on multiword expressions: from parsing and generation to the real world. Association for Computational Linguistics, Portland, Oregon, USA, 2011.

GROSS, M. Grammaire transformationelle du français. V. 1. Paris: Larousse, 1968.

GROSS, M. Métbodes en syntaxe. Paris: Hermann, 1975. 
GROSS, M. Les bases empiriques de la notion de prédicat sémantique. Langages, n.63, p.7-52, 1981.

GROSS, M. Une classification des phrases "figées" du français. Revue québécoise de linguistique, v. 11, n. 2, p. 151-185, 1982.

GROSS, M. La fonction sémantique des verbes supports. Travaux de linguistique. Bruxelles: Duculot, n. 37, p. 25-46, 1998.

HARRIS, Z. S. Structural linguistics. University of Chicago Press, 1951.

HARRIS, Z. S. Transformational theory. Language, n. 41, p. 363-401, 1965.

JESPERSEN, O. A modern English grammar on bistorical principles. Part VI, Morphology. London: George Allen and Unwin, 1965.

LA FAUCI, N.; MIRTO, I. M. Fare: elementi di sintassi. Pisa, Itália: Edizioni ETS, 2003.

NEVES, M. H. M. Estudo das construções com verbo-suporte em português. In: KOCH, Ingedore Villaça (Org.). Gramática do português falado. v. VI: Desenvolvimentos. Campinas, SP: Editora da Unicamp, 1996.

PAUMIER, S. Unitex: manuel d'utilisation, research report. França: University of Marne-la-Vallée, 2002.

RUPPENHOFER, J.; ELLSWORTH, M.; PETRUCK, M. R. L.; JOHNSON, C.; SCHEFFCZYK, J. FrameNet II: extended theory and practice, 2006. Disponível em: <www.FrameNet.icsi.berkeley.edu > . Acesso em: 20 abr. 2012.

VALE, O. A. Expressões cristalizadas do português do Brasil: uma proposta de tipologia. 2001. Tese (Doutorado) - Unesp, Araraquara, 2001.

Recebido para publicação em 31 de julho de 2013 Aprovado em 2 de outubro de 2013 